\title{
Application of Flower Border in Northern Gardens
}

\author{
Miao Liu \\ College of Forestry, Shandong Agricultural University, Tai An, 271000, China \\ liumiao2019123@163.com
}

Keywords: Northern garden, Flower border, Application

\begin{abstract}
Starting from the concept of flower border, and classifying the flower environment according to various aspects of plant material, application scene and flower viewing characteristics; introducing the principles of flower plant material selection and common plants in northern gardens and detailing the flower garden in the northern garden in the application.
\end{abstract}

\section{Introduction}

With the improvement of people's living standards, people's appreciation of garden landscape has been continuously improved, and the requirements for the aesthetics and functional utility of landscaping are also increasing. Therefore, environmental beautification and garden construction have received people's attention. Through the combination of different colors and morphological plants, the flower border achieves the natural and vivid, leafy and vigorous plant landscape effect, and has the function of separating the space and organizing the tour route. Therefore, the application of the study flower border in the garden is particularly important.

\section{Flower border concept}

The flower world originated from the West, the word Flower border in English, translated into flower or flower path. The traditional concept of flower environment is to simulate the state of interlaced growth of various wild flowers in the forest edge of nature. It is mainly composed of perennial flowers and flower shrubs. It is artistically refined into a wide or narrow curve or linear natural flower band, showing flowers. Naturally scattered landscape. We draw on the concept of flower borders at home and abroad, and define the flower environment as the main material of perennial flowers, flowering shrubs, etc., and plant them in the form of natural patches in the forest edge, roadside, wall sill and the center of the lawn. A form of garden planting that achieves natural harmony in height, color and season.

\section{Classification of flower borders}

There are many classification standards for flower landscaping forms, which can be classified according to the plant material of the flower environment, or according to the application site, and can also be classified according to factors such as plant biological characteristics or environmental conditions. 
a) Classified by plant biological characteristics

It can be divided into herbaceous flower environment, mixed flower environment and conifer flower environment. The ornamental grass flower environment belongs to the category of herbal flower environment, and the mixed flower environment and ornamental grass flower environment are the new favorite of plant landscape in Europe and America in recent years.

(1) Herbal flower border

The plant material is mainly composed of perennial herbaceous flowers and one-and-two-year-old flowers. It is often in the form of flowering in the spring, summer and autumn. It is an early form of flower environment, also known as grass flower border.

(2) Mixed flower border

Using herbaceous plants and woody plants as materials, climbing plants and ornamental grasses are used as framed plants. One-two-year-old, perennial herbs and bulbous flowers are used as the main flowering plants in spring and summer, and plants of different textures, plant shapes and colors are mixed and planted. To create an annual changing landscape. The flower garden built with various perennial ornamental grasses is called ornamental grass flower environment. It is a plant landscaping form that is very popular in Europe and America in recent years. Ornamental grasses are mainly grasses, including some sedges, rushes, and buds.

(3) Ornamental grass flower border

Ornamental grass refers to the general name of gramineous plants that use stalks, leaf clumps and inflorescences as the main ornamental parts for garden landscaping. It also includes some plants such as sedge, genus, and genus.

(4) Coniferous flower border

Specifically refers to the coniferous conifers as the main landscaping elements, using the evergreen nature of plant materials and the slow growth characteristics of herbaceous flowers, the theme created by the different characteristics of the arrangement of the type of irrigated, the landscape form with strong landscape continuity.

b) Classified by application scenarios

According to the different forms of flower garden in garden application, it can be divided into forest edge flower border, curb flower border, wall flower garden, lawn flower environment, waterfront flower environment and garden flower environment. The first three are usually arranged in a strip shape, and the lawn flower environment is often arranged independently, while the garden flower environment needs to be adapted to local conditions and the landscaping style is different.

(1) Forest edge flower border

Mostly in the background of evergreen or deciduous shrubs, it is distributed as a transitional plant community that is connected to the turf.

(2) Curb flower border

Refers to the flower border beside the trail in the garden, which can be arranged either unilaterally or bilaterally. If there are sculptures, fountains and other landscape pieces at the end of the road, it can play a guiding role.

(3) Wall and flower border

Retaining walls including wall rims, hedges, fences, fences, tree walls or sloping fields and flower fronts in front of buildings are collectively referred to as wall slabs.

(4) Lawn flower border

Located in the center of the lawn, green space or on the edge, usually on a double-sided or four-sided flower arrangement. It can organize both the tour route and the landscape space.

(5) Waterfront flower border

The main plant material is a perennial herb or shrub that is resistant to water and moisture, and is often arranged in a strip shape to form a beautiful landscape along the water body. 
(6) Garden flower border

The flower garden is often used in the area enclosed by the courtyard, garden or building. It can be arranged in the surrounding area or in the center of the courtyard. It is the most commonly used form in foreign flower gardens, especially in the English garden. classic.

c) Classified by flowering

The main purpose of creating a flower environment is to observe the flower effect. Usually, depending on the flowering period, it can be divided into early spring flower environment, spring and summer flower environment and autumn and winter flower environment. It can also be further subdivided into early summer flowering, midsummer flowering and winter flowering.

(1) Early spring flower border

The main plant material is the flower that blooms in early spring. It is the recovery of all things in spring, reaching the landscape effect of vitality and growth of all things.

(2) Spring and summer flower border

The main plant materials are perennial flowers and autumn-selling one-and-two-year-old flowers. During this period, the most flowering plants are planted, which can create landscapes with rich colors and lush foliage.

(3) Autumn and winter flower border

It mainly displays autumn and autumn through autumn leaf species, fruit trees, ornamental grasses, etc., usually with evergreen plants to avoid the ridiculous winter landscape.

d) Other classification forms

Flower borders can usually be divided into single-sided flower and double-sided flowers according to the viewing angle. Single-sided flower gardens often use buildings, low walls, trees, hedges, etc. as backgrounds. The plant arrangement is generally low and high, with tall plants as backgrounds and low plant borders for visitors to watch on one side. Double-sided flower fields usually have no background, and are often placed on the lawn or between the trees. The planting is high in the middle and low on both sides, allowing visitors to watch on both sides or on multiple sides.

According to the different site conditions of the flower environment, it can also be divided into various forms such as the flower garden, the flower field, the clay flower environment, the sand flower environment and the wetland flower environment.

\section{Selection of flower border material}

a) Principles of plant material selection

(1) Choose native plants

Native plants have strong adaptability, strong growth and strong resistance, which is conducive to maintaining the lush landscape of the flower landscape.

(2) Choose plants with longer flowering periods

Different flowering plants are needed throughout the year to ensure the richness and ornamental of the landscape. Plants with long flowering period can bloom for a long time, maintain long-term vitality in a season, improve the fun of the flower environment, and avoid the monotony of the landscape.

(3) Choose plants with strong cold resistance and long life

Most of the northern part of China is a temperate continental climate. The basic characteristics are cold winter and hot summer, and large temperature difference. Therefore, plants that can be exposed to winter in the northern region and can survive for 3-5 years should be selected to save costs while ensuring beautiful flower environment. 
b) Common plants in northern gardens

Early spring flowering flowers often have narcissus, tulip, poached peony, hawthorn cohosh; spring and summer flowering commonly used flowers are mainly flowering golden pheasant, perennial delphinium, horse owl, iris, yellow iris, wrinkle leaf cut Charo, large flower Binju, Columbine, Jintuan Dianthus, Liqinghua; common flowers in summer are mainly phoenix, hollyhock, canna, dahlia, gladiolus, yarrow, jade, brook, lycopodium, perennial phlox, evening incense Jade, platycodon, and vegetables; the flowers that bloom in autumn mainly include gerbera, wild chrysanthemum, one ear, Zeeland, and scorpion grass.

\section{The practical application of flower border in the north}

a) Park flower border

(1) Center of the square

At the center of the square, there are generally large flower beds, sculptures, fountains, rockeries and other landscapes. In the middle of the flower beds, tall and neat flowers, such as canna, foxglove, high Snapdragon, broom grass, etc., can also be used. Some trees, such as bauhinia, can also be used. Lagerstroemia, palmetto, phoenix orchid and trimmed spherical boxwood, cypress, etc.; often design large-scale embossed shapes, commonly used plants are scutellaria, fragrant snowballs, dwarf scented grass Etc., gradually transition to shrubs, flowering shrubs, such as rose, peony, delphinium, wrinkle cut Charlotox, etc., and finally transition to perennial or annual dwarf flowers, such as petunia, balsam, alfalfa, chrysanthemum A bunch of red, peacock grass, etc., can be planted on the edge of some foliage plants, such as colored grass, brook, valerian, purple duck grass and so on. In the overall layout, attention should be paid to the color matching, the layering and the sense of the scenery, and the vivid atmosphere to meet different viewing needs.

(2) Park guide signs and rockery signs

Set a small area of flower space, at the corners of several roads, usually use the highly similar, brightly colored plant materials to match, can attract the attention of tourists, playing a guiding and guiding role.

(3) Walking along the boardwalk and the edge of the forest

The foreground is mainly composed of low-grade one-and-two-year-old flowers, such as peacock grass, a string of red, clustered phlox, petunia, coleus and so on. The medium-level is mainly erect herbs, such as snapdragon, foxglove, blue-bellied sage, etc. The background is often used to form evergreen broad-leaved forests such as camphor, metasequoia, and magnolia, which play a role in setting off the natural sputum. The lines form a certain sense of rhythm and rhythm, giving people a visual sense of pleasure, and walking on the road is not boring.

(4) Walking road section

It can be used for both pedestrians and roads. The natural flower arrangement with the patchwork can complete the connection between the road and the landscape, and expand the space to form a beautiful landscape.

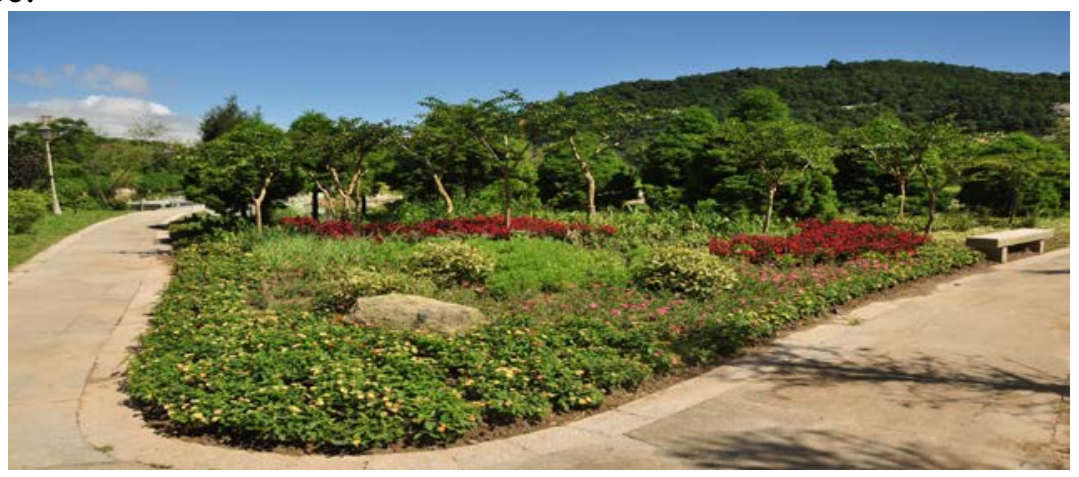


b) Wall flower border

In the low buildings, fences, fences, fences, flower stands and other structures can be set in front of the flowers, can soften the hard lines of the building, and integrate them with the surrounding natural scenery to play a transitional role. When selecting plant materials, attention should be paid to the differences and combinations of plant materials in plant type, leaf shape, leaf color, flower color, etc. The colors can be bright and strong, fresh and elegant, and the colors are not messy, the main colors are clear, and the colors are clear. There are echoes, excessive and mutual reconciliation; through the high and low, the combination of density, density, color, size and other plant characteristics to show the layering of the flower and the rich facade effect. Some plant materials such as delphinium, foxglove, scutellaria, and stalks show the vertical lines, which not only show the vitality of the landscape, but also extend the vertical space of the building; The horizontal space beside the rich structures such as Petunia, a string of red, etc., not only beautifies the monotonous buildings, but also meets the ecological needs of people.

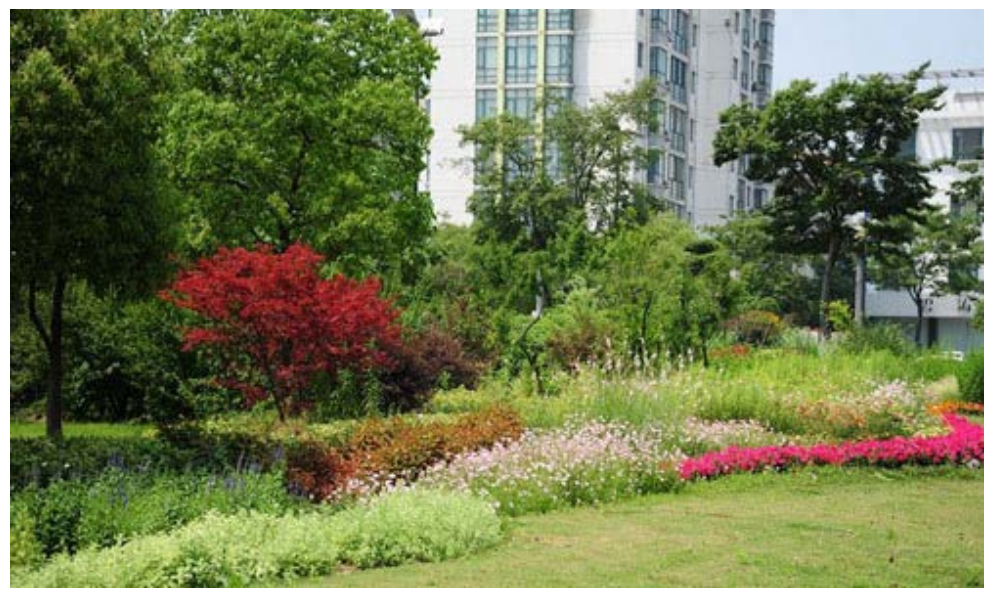

c) Road flower border

(1) Pedestrian zone green belt

The green belt arrangement in the pedestrian zone should pay attention to the color and quantity of various flowers in the same season and the continuation of the four seasons landscape, creating a natural landscape that allows pedestrians to walk comfortably while at the same time enriching plant diversity and increasing Natural landscapes, separation spaces and the role of organizing tours.

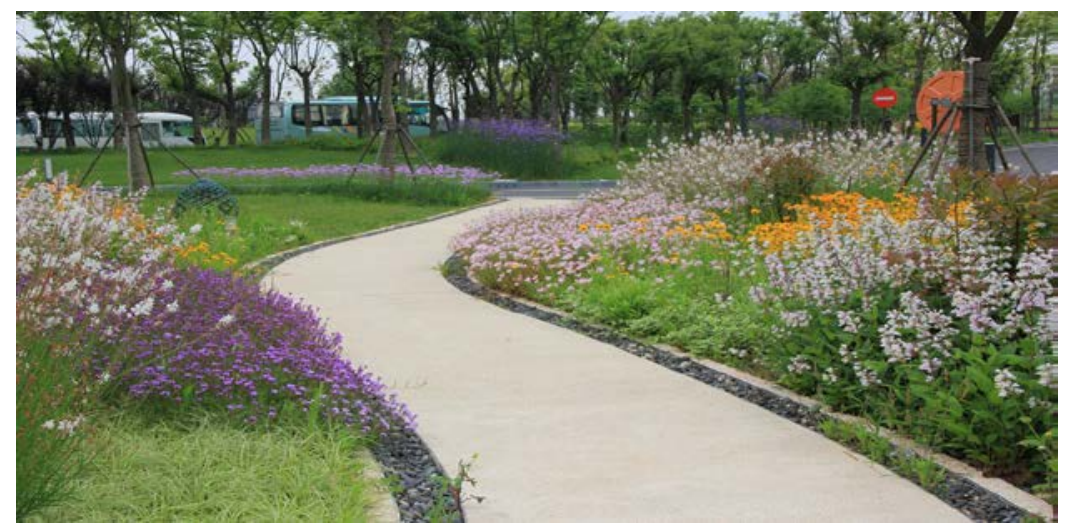

(2) Car with node flower border

After a long period of continuation of a green belt with the same landscape law, the vehicle belt node is an important variation point, using the flower environment to create a bright and pleasant 
visual effect, so that the driver waiting for the green light relieves the aesthetic fatigue.

(3) Traffic green island flower border

The plant material here is mainly composed of evergreen shrubs, perennial flowers and ornamental grasses. It is dotted with a small amount of one-and-two-year-old flowers. It is not necessary to pursue colorful colors. It is necessary to ensure that the flower environment has a long-term viewing effect and that the driver is guaranteed. Gain visual appreciation without being disturbed by excessively chaotic colors.

(4) Road side green belt flower border

The background of road flower arrangement is mainly composed of shrubs and shrubs, which are scattered with perennial flowers. They pay attention to the embellishment of ornamental grasses and ferns. They use one or two-year-old flowers to enhance the diversity of landscapes and form a belt-like landscape with a sense of layering and rhythm.

d) In the community, in the courtyard

With the progress of the society and the development of the times, people's living standards have gradually improved, and more and more attention has been paid to the quality of the living environment. I hope that I can live in an environment with fresh air and natural wildness, and the flower environment will become the best choice for the green community. The flower environment can be arranged in a small garden or arranged according to the terrain. It can be designed in one form, double-sided, corresponding and other forms, but all must follow the principle of flower design, and finally achieve natural harmony and richness. Landscape effect. The flower garden in the community or courtyard can smell the three seasons, and the four seasons can be seen, full of the vitality and vitality of nature.

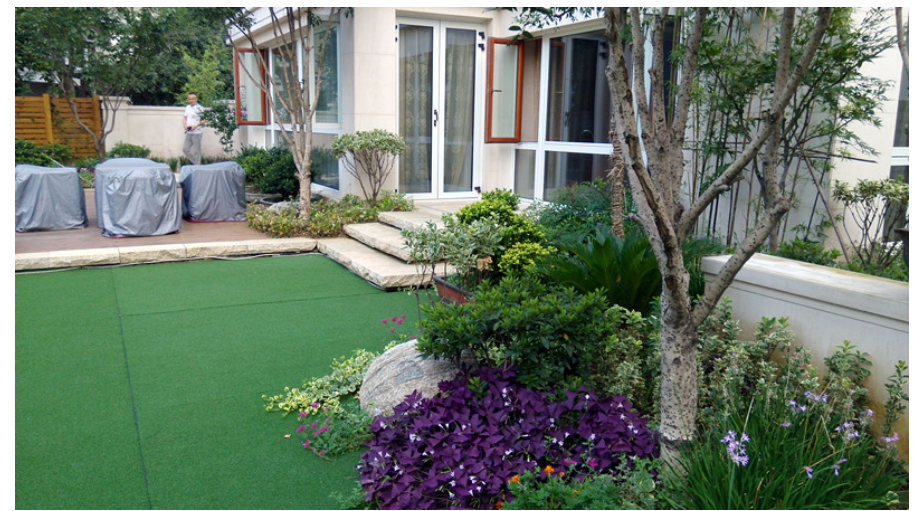

e) Waterfront flower border

The arrangement of flowers on the waterfront can enhance the beauty of the water surface, provide the focus of people's attention, and enrich the coastal landscape. In the shallow water area, wet plants such as yellow iris, lycopodium, cattail, reed, etc. can be arranged, swaying on the surface of the water to enhance the water landscape effect; the hollyhock and blue sage can be planted outwards, Jinshan Spiraea and Cosmos form a medium-sized scene; plants such as Stipa sylvestris and Pennisetum sway in the wind, which can increase the dynamic beauty of the flower environment, contrast with the hard landscape such as riverside structures, and soften the hard lines; The configuration of plant materials such as peacock grass, beautiful cherry, nasturtium, and musk vines creates a bright and beautiful flower environment. 


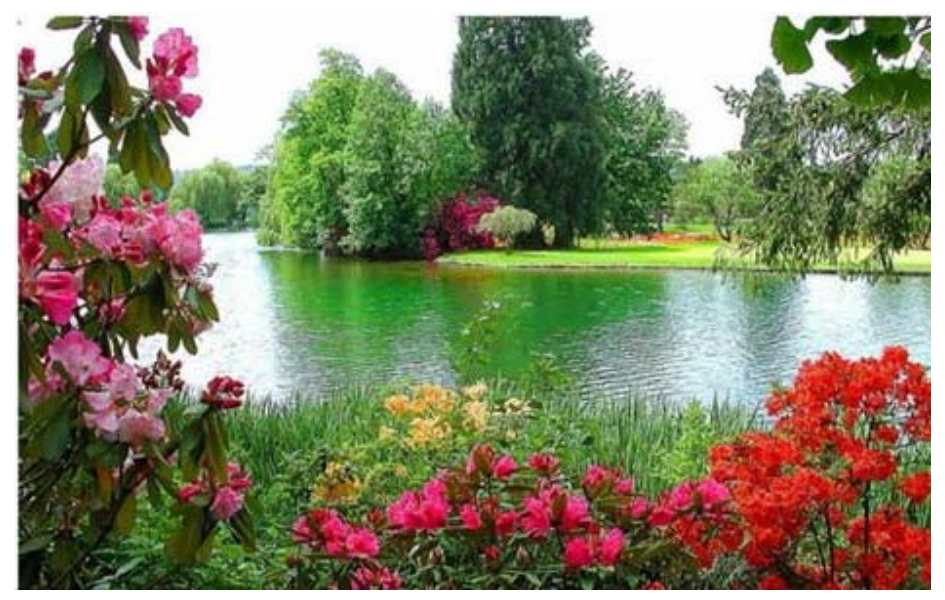

\section{Conclusions}

China has a wealth of flowering plants, and the flower environment also has a wide range of landscape and garden applications. According to the characteristics of the flower environment, their use has room for further improvement. While learning the landscape of landscapes, garden designers should strive to develop potential plant material resources, and appropriately introduce domestication, combine the key points of flower planting, and improve the artistic aesthetics of flower borders and the flexible use of sensory mental functions of flower borders. Research more exciting grass flower and flower mirror decoration methods to create a more attractive urban garden landscape, and make the city's environment more and more beautiful.

\section{References}

[1] Mi Jie. Application of flower environment in northern gardens. Inner Mongolia Forestry [J], 2007, (8): 30-31.

[2] Zhang Min. Application of flower border in park landscape. Technology and market (garden engineering) [J], 2007,

(5): 36-37.

[3] Liang Kuihua, Liu Jieqi. Application of flower border in park landscape. Chinese Horticultural Digest [J], 2016,

(12): 172-173.

[4] Guo Zhuo. Flower type and design points. Chinese Horticultural Digest [J], 2011, (1): 106-109.

[5] Feng Yan. Application of flower field planting in garden engineering construction. Beijing Agriculture [J], 2013, (9): 48.

[6] Jiang Guanghong, Li Zhengqiang, Zhang Wei, Xie Min, Liu Bingyou. Flower beds, flower arrangement and flower configuration. Chinese Horticultural Digest [J], 2012 (3): 114+100.

[7] Ding Haijun. Example of the configuration of road flower environment_-taking Shanghai and Hangzhou as examples. Garden Garden[J], 2013, (8): 72-75.

[8] Gao Yahong, Wu Yufei. Guide to Flower Plant Selection [M]. Wuhan: Huazhong University of Science and Technology Press, 2010.

[9] Department of Flowers, Beijing Forestry University, Flower Teaching and Research Group. Flower Science [M]. Beijing: China Forestry Publishing House, 1999.

[10] Ding Shaogang. Landscape Architecture-Landscape Designer's Handbook [M]. Shanghai: Shanghai Science and Technology Press, 2009.

[11] Liu Xiaohui. Wen Xin's Paintings: Analysis of the Elements of Chinese Classical Landscapes [M]. Beijing: China Building Industry Press, 2002.

[12] Peter Robinson. The Practical Rock and Water Garden. London: Hermes House, 2007.

[13] Darrel Apps. Perennial Border Design with Foliage: Greating Beds and Borders. USA: The Taunton Press, 2001. 